\title{
Optimisation of a Spindle Body Considering the Vibration Prediction of the Entire Milling Centre Construction
}

\author{
Mateusz WĄSIK*, Krzysztof LEHRICH**, Krzysztof LIS*** \\ *Silesian University of Technology, Machine Technology Department, Konarskiego 18A, 44-100 Gliwice, Poland, \\ E-mail:wasik.mateusz@hotmail.com \\ **Silesian University of Technology, Machine Technology Department, Konarskiego 18A, 44-100 Gliwice, Poland, \\ E-mail: krzysztof.lehrich@polsl.pl \\ ***Silesian University of Technology, Machine Technology Department, Konarskiego 18A, 44-100 Gliwice, Poland, \\ E-mail: krzysztof.lis@polsl.pl
}

crossref http://dx.doi.org/10.5755/j02.mech.24429

\section{Introduction}

The continuous development of technology presents new solutions while dictating new development trends. Some solutions commonly used for many years no longer correspond to evolving and emerging needs. The development of related fields of science eliminates many contradictions in the application of given technologies in the field of machine tool construction and creates new possibilities for constructors. In case of optimisation, in order to reduce the consumption of structural materials weight and emissions of harmful chemicals into the atmosphere, combined with and constantly growing economic demands of the market regarding achieved accuracy of dimensionally shaped workpieces and achieved cutting speeds become a major factor driving the need to develop and introduce innovative solutions in the field of optimal design of machine tool bodies. On the other hand of the demand there are still many unresolved problems of classic methods of machine tool bodies design.

The machine tools for high-speed machining (HSM) have been the dominating direction for the development of machine tools for over a decade. A significant change in the operating parameters of such machine tools results in enhancement of phenomena, which earlier were not so important in case of machines characterised by "conventional parameters". This applies to, among others, an increase in the power of heat sources, such as feed motors and integrated main propulsion engines in form of electro-spindles, bearing nodes, helical-wheel transmissions in classical drives and linear motors. The increase in the dynamics of movements requires a reduction of weight of components such as spindles, stands, sleighs and tables. However, the weight reduction cannot be accompanied by a decrease in stiffness [1-5]. Therefore, due to the complexity of the phenomena accompanying the operation of a HSM machine tool, it is necessary to change the design approach. The still valid approach based on the use of constructional solutions from already produced machine tools of conventional work parameters should be changed into a design process considering the possibilities offered by FEM simulations in the field of thermomechanical, mechanical and flow analysis and optimisation.

In most cases, structural optimisation is carried out in order to reduce the weight of the elements, for example, under the assumption that the reduced stresses are within acceptable limits. Such approach has mainly economic justification and has low priority in the case when optimizing the bodies of machine tool structures. For machine tools bodies, optimisation goals can be divided into optimisation of load-bearing structures, i.e. fixed structures such as racks, slide beams, beds and optimisation of moving structures such as headstocks, sledges, slides. For fixed bodies, the aim of optimisation can be to maximise stiffness while minimising weight. For movable bodies, the main objective is to minimize weight while maximizing static stiffness. In this case, the minimisation of mass allows for a sufficiently high dynamics of movement, and the economic aspect is revealed when selecting a drive train that can be cheaper in this situation.

In this article, the authors have set the goal of optimizing the headstock body of a milling headstock to obtain a structure with the lowest possible mass and at the same time its stiffness at the level not less than the stiffness of the original developed by an experienced designer, not supported by numerical calculations in optimisation. This article presents two approaches to the design of a movable body using the optimisation process. The first approach shows how a process, in which the structural form is based on the knowledge of an experienced designer and where only a part of geometric dimensions is optimised, could look like. In the considered case, only the possibility of changing the thickness of individual body walls was taken into account. In the other case, it is shown how the body design process, in which topological optimisation is first applied on the basis of which the initial geometric form of the body is created, and in the next design stage, dimensional optimisation of the proposed design form is carried out, should look like. The approach is based on the capabilities and algorithms available in the commercial FEA software, which gives the utilitarian nature of the work.

\section{Materials and methods}

\subsection{Subject of the study}

The stand, as one of the most significant elements influencing the static and dynamic properties of the whole machine was optimised first. The tests were carried out on a machine stand of shape and dimensions obtained in the optimisation process based on genetic algorithms. The design and optimisation process have been described widely in [6, 7]. At this stage, the construction (yet without the spindle 
design) was made and its dynamic properties were examined subsequently. The examination of the dynamic properties was conducted shortly after manufacturing the body on a temporary experimental station. The analysed body is a part of a research and teaching station developed in the Machine Technology Department at the Silesian University of Technology [8 - 12]. In the original design proposed by the constructors, the analysed bodies were elements of the support structure of the milling centre (Fig. 1). An exemplary machine (Fig. 1) includes 3 moving bodies (headstock, stand and saddle) driven by individual motors. For those bodies some specific demands are needed, among others high dynamic properties-high accelerations in transient states (up to $1 \mathrm{G}$ ). For this reason, it is important to designate the dynamic properties of the machine of moving bodies.

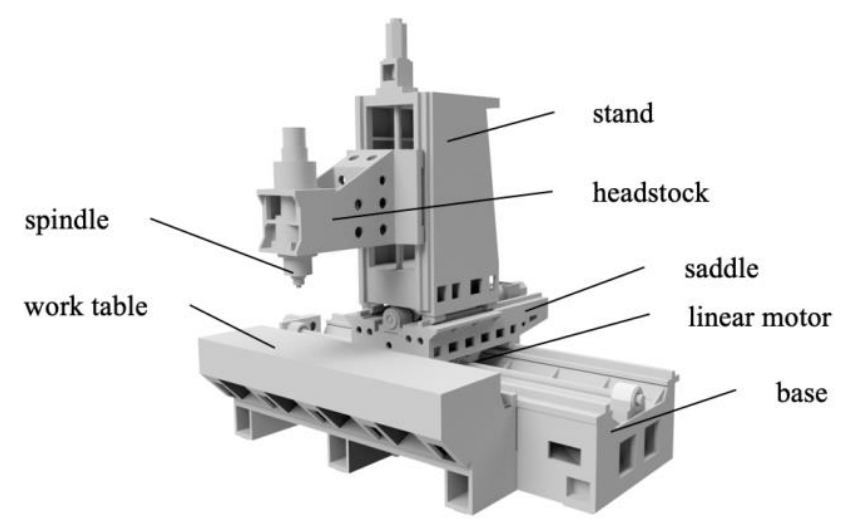

Fig. 1 CAD model of the analysed milling centre

Table 1

Mode shapes and natural frequencies for seven first modes. Comparison of FEM and experiment results

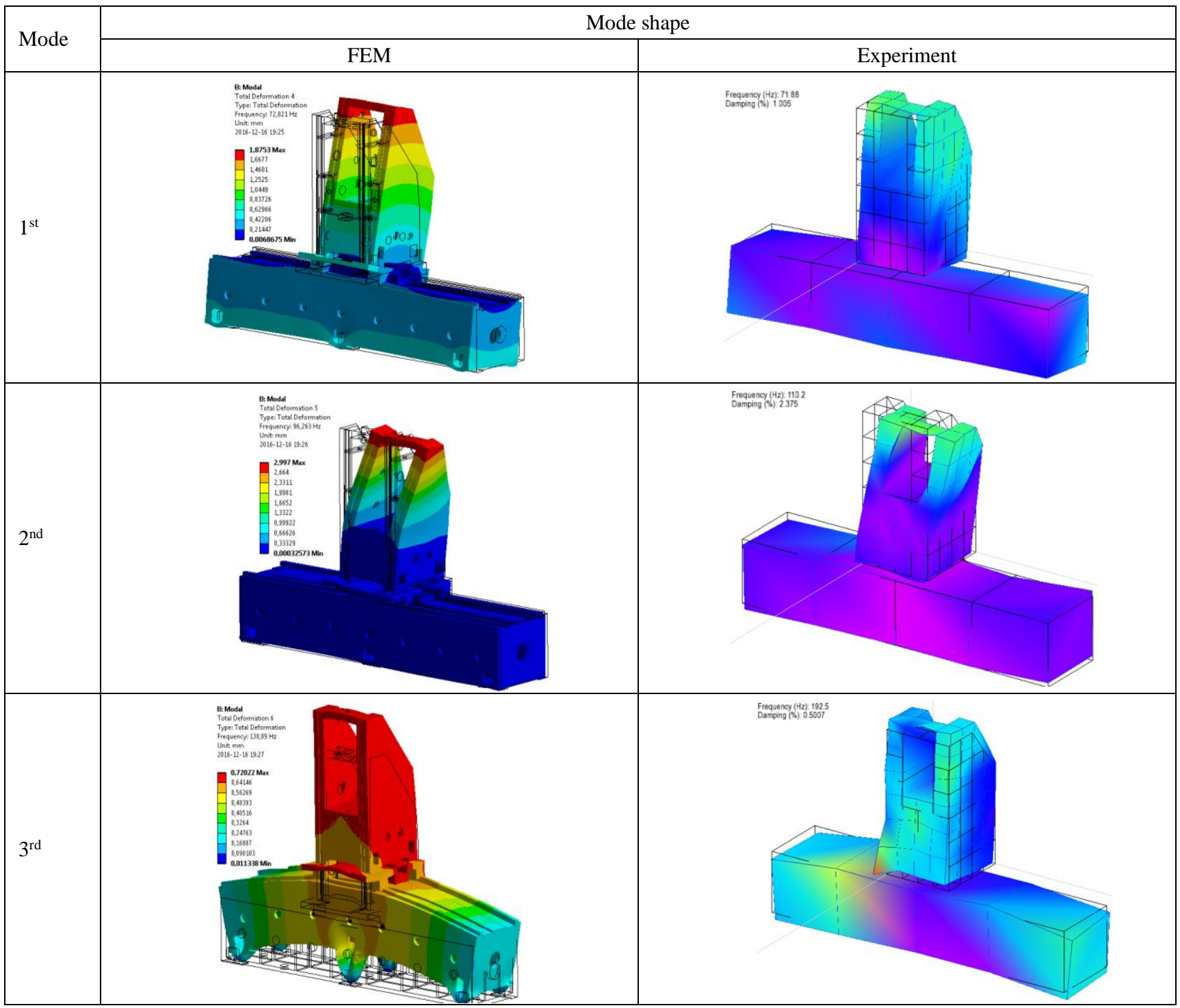

The stand body is casted from cast iron. Milling centre bodies, like most of the machine tools bodies, are characterised by dense internal ribbing. The prototype of the machining centre comprises a plurality of moving (sliding) and fixed bodies (Fig. 1). From the possible configurations of the spatial region, a work area (area in the form of a cuboid) is created, within which the machining can be carried out. In the analysed case, only the extreme position of the mill stand has been considered. Basing on the models of individual geometric bodies (3D models) proposed by an experienced designer, the numerical models for a finite element analysis have been developed.

In order to evaluate the frequency and normal modes, verification tests were carried out by using experimental modal analysis based on the principle of Maxwell's reciprocity. The extortion in this method is a pulse generated 
by a modal hammer, the response is recorded using a threeaxis acceleration sensor. Basing on experimental studies, the first characters and the frequency values of eigen modes were identified. Obtained results are summarised below with the results of the FEM analysis of the milling centre stand body. Table 1 includes the comparison of the mode shapes (first 3 frequencies)-visualisations obtained in FEM and visualisations of the mode shapes from the experiment. Table 2 shows the comparison of results obtained from FEM and the experimental model for individual modal characters

Table 2

Modal frequencies for seven first modes.

Comparison of FEM and experiment results

\begin{tabular}{|c|c|c|c|}
\hline \multirow{2}{*}{ Mode } & \multicolumn{2}{|c|}{ Frequency, Hz } & \multirow{2}{*}{ Difference, \% } \\
\cline { 2 - 3 } & FEM & Experiment & \\
\hline $1^{\text {st }}$ & 72.821 & 71.88 & 1.3 \\
\hline $2^{\text {nd }}$ & 96.263 & 110.2 & 14.4 \\
\hline $3^{\text {rd }}$ & 138.09 & 192.5 & 39.4 \\
\hline $4^{\text {th }}$ & 210.43 & 269.7 & 28.1 \\
\hline $5^{\text {th }}$ & 218.95 & 207.3 & 5.6 \\
\hline $6^{\text {th }}$ & 250.36 & 277.1 & 10.6 \\
\hline $7^{\text {th }}$ & 284.38 & 301.2 & 5.9 \\
\hline
\end{tabular}

An exemplary analysis gives an insight into the applicability of this technique to prediction of prototype structure parameters and can be used in machine tool construction. Fig. 2 shows an example of a modal structural modification of machine tool body in the Modal VIEW software [13, 14]. The implantation of the spindle was carried out by inserting the mass in the points indicated in the drawing of the structure.

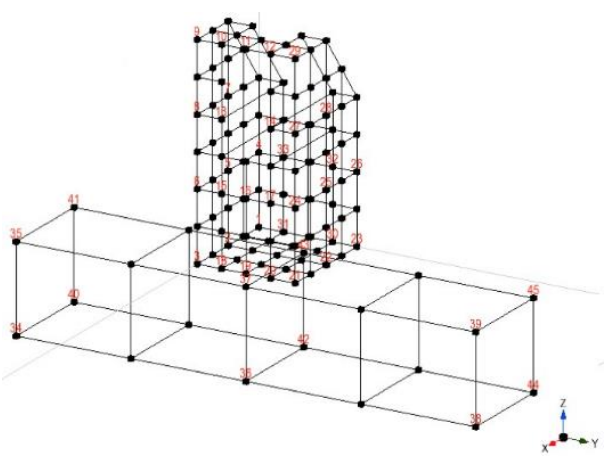

a

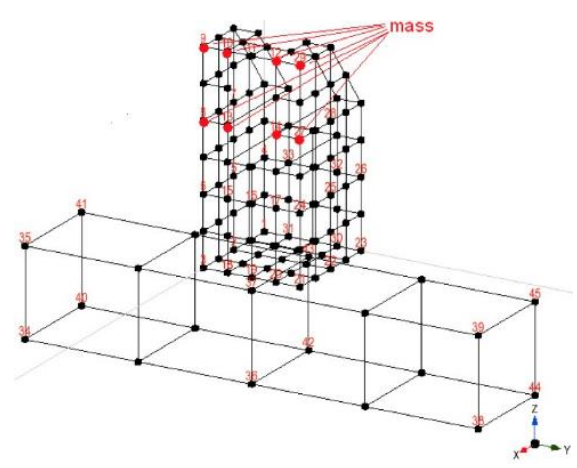

b

Fig. 2 Tested structure with marked modal points (a) and additional mass in modal structural modification of machine tool body (b)
The applied modification results in a change of the modal parameters of the milling centre. Fig. 3 illustrates an exemplary FRF showing the change in the frequency of the internal vibration for two different masses distributed in the points (Fig. 2). The process of machine tools dynamic structural modification was precisely presented and described in [15]. In the next steps, an attempt to construct a spindle using optimisation methods was made.

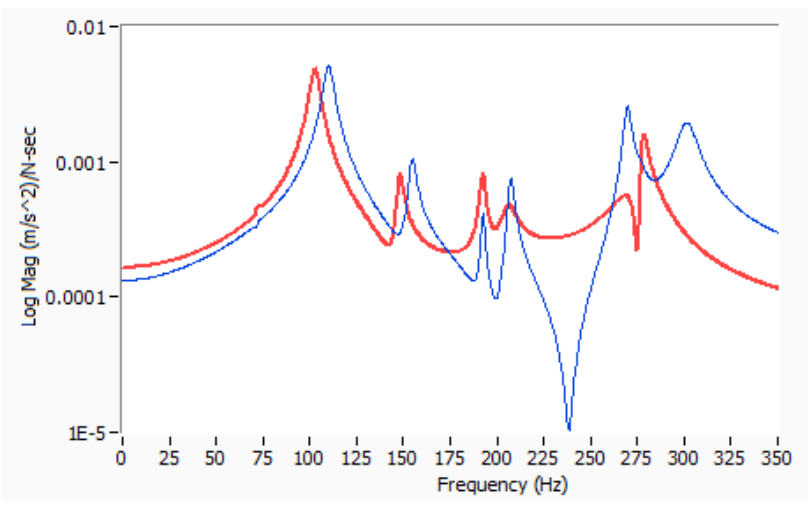

a

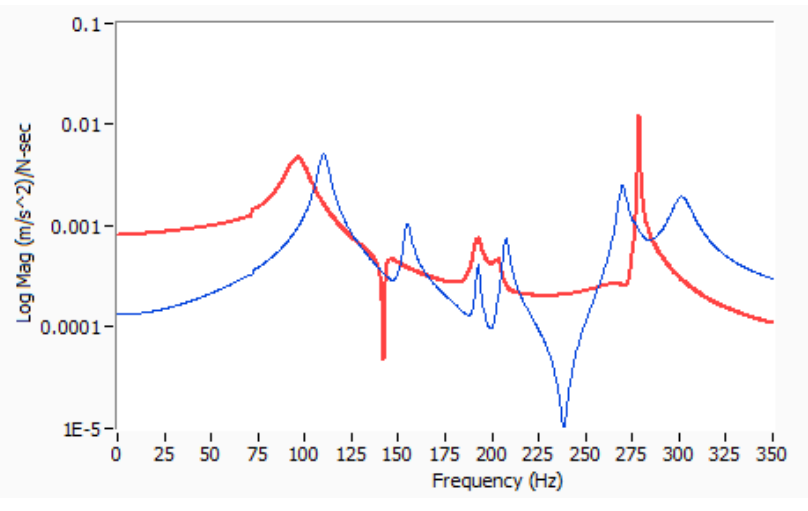

b

Fig. 3 FRF plot for structural dynamic modification. Blue plot - Input DOF 11Y (force applied in point 11 in Y direction), red plot - output DOF 44Y (output measured in point 44 in $\mathrm{Y}$ direction) for two different masses. a) lower mass $m_{1}$, b) higher mass $m_{2}$

\subsection{Headstock optimisation}

The analysed problem of machine tool bodies deformations can be considered in the category of multicriterial optimisation problems. In a general case, as a part of the optimisation, three main parameters are subject to the modification (Fig. 4):

- $q_{1}(x)$ - mass;

- $q_{2}(x)$ - static stiffness of the machine tool;

- $q_{3}(x)$ - first modal frequency.

Therefore, the presented problem can be defined as an attempt to find a vector of decisive variables. There are several approaches to solve multicriterial optimisation problems, including task scalarisation or the Pareto approach [16].

Defining the basic and dominant criterion, as well as assessing the significance of the other ones, allows to transform a multicriterial issue into a single-criterion one, according to a simplified scheme (Fig. 4). Attention should 
be paid to the fact that both the quantitative and qualitative criteria are considered in the analysed problem. In case of a multicriterial problem, this implies the necessity of changing the value of the qualitative feature to numerical values in order to unify the criteria and enable the optimisation (standardisation of criteria).

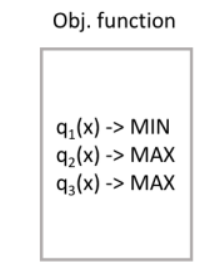

$F(x)=\left\{q_{1}(x), q_{2}(x), q_{3}(x)\right\}$
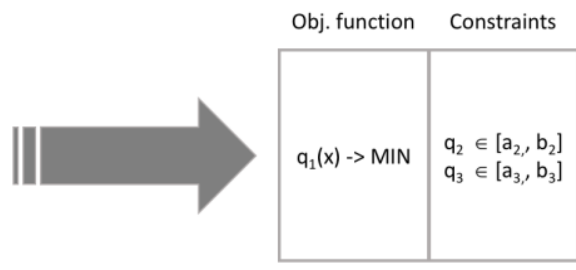

$F(x)=q_{1}(x)$
Fig. 4 Simplified scheme for transforming a multicriterial problem into a single criterion

To proceed to the optimisation, a certain number of computational analyses should be performed. FEM analysis for complex models is very time consuming. In order to shorten the whole process, it is necessary to apply some simplifications. The main simplification is the abandonment of the use of contact elements necessary to determine the stiffness of the contact, which allows for the use of a linear model calculations, that is much less time-consuming when it comes to calculations. Therefore, the obtained stiffness values of the machine cannot be related to the results obtained during the experimental tests but are sufficient as a reference for the optimisation result.

\subsection{Parametric optimisation}

Parametric optimisation was performed first basing on the body form proposed by the designer (Fig. 1). Only the thickness of the walls and ribs of the body were optimised. The optimisation did not take into account the possibility of changing the number of ribs and their position. The unchanged dimensions of the body were also assumed.

Due to the fact that the headstock is a mobile body, the main goal of the optimisation was to reduce the mass, while maintaining static stiffness at a level similar to the stiffness of the body determined for its original dimensions. Parametric optimisation $[17,18]$ in the ANSYS DesignXplorer module can be carried out by various methods. The MOGA (Multi-Objective Genetic Algorithm) method, a hybrid variant of the NSGA-II (Non-dominated Sorted Genetic Algorithm-II) method, was used to optimise the headstock body. The limitation of this method is the possibility of using it only in the case of solving tasks with continuous variables. The thickness of the body walls was taken as the decisive variables for optimisation (Fig. 5).

The milling centre model was loaded at the tool mounting location as shown in Fig. 6. The value of the loading force for static stiffness tests equals $10 \mathrm{kN}$ and was given independently in three directions. The headstock body was fixed at the place where the ball nut was mounted, while on the surfaces of guide carriages cooperating with guides, the possibility of movement was provided only in the direction indicated by the guides (Fig. 5). For the body of the headstock, material properties corresponding to the properties of cast iron were adopted, while for elements such as guide trucks, the properties specific to steel were adopted.
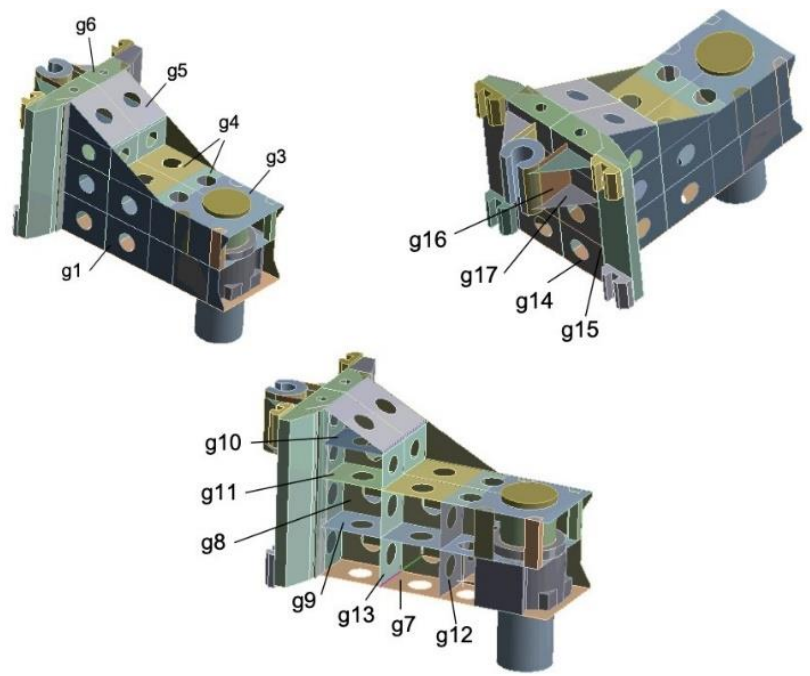

Fig. 5 The form of the headstock and the indication of wall thickness
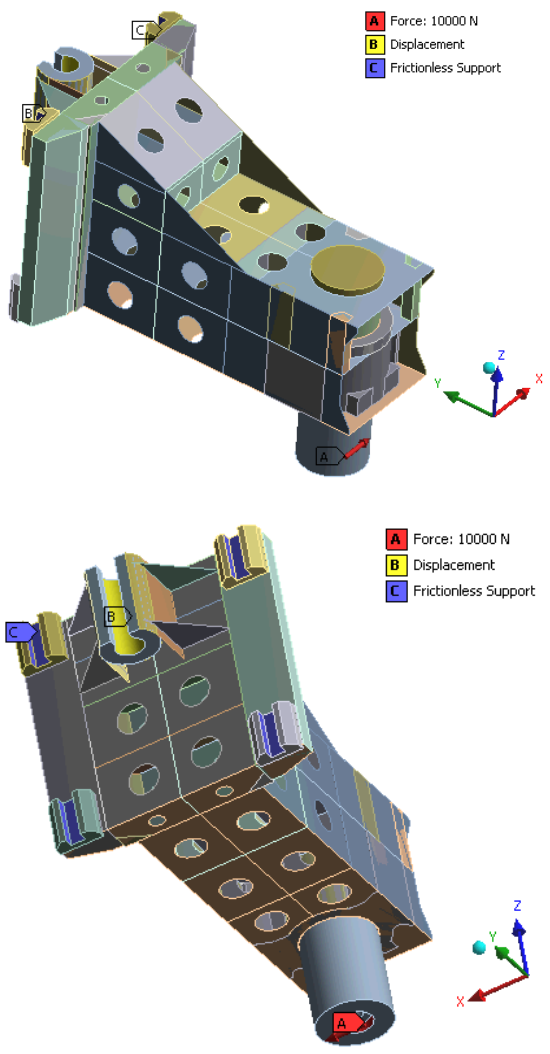

Fig. 6 The boundary conditions adopted for the parametric optimisation of the headstock

\subsection{Topology optimisation}

The topological optimisation of the headstock body was carried out, assuming a simplified geometric form of the body as the initial form (Fig. 7). Dimensions of the solid, similar in form to a cuboid, correspond to the overall dimensions of the body proposed by the designer. Formal optimisation was carried out for various load cases, assuming a method of support and load analogous to the original body assumed in the analyses. During the optimisation, the program searched for the optimal path of energy flow and generated empty spaces in the model. The results of the form optimisation are presented below (Figs. 8 - 10), showing the shape of the body resulting from the assumed load. 

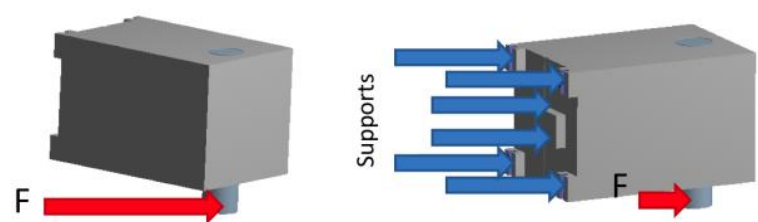

Fig. 7 Simplified geometric form of the spindle head for topological optimisation

The conducted optimisation process is based on the SIMP (Solid Isotropic Microstructure with Penalization) method [17-21]. The SIMP method is a topology optimisation method for isotropic, porous or composite material continuum. It is one of the GSO (Generalized Shape Optimisation) optimisation methods. The optimisation process is conducted inside a limited design area which is divided to subareas filled or not filled with a material. During the optimisation, the borders of the design area subareas are changing. The SIMP method is used for numerical optimisation with cooperation with the use of common numerical tools such as Finite Element Method (FEM) [22]. The described method eliminates the material from the elements that belong to the design area and have defined virtual low-density substitute material. According to the SIMP method, it is required to use a properly defined and updated Young modulus and the material density for several finite elements. The substitute material takes values between the set value (maximal) and zero. In this case the substitute material is a fictional material.

\section{Results and discussion}

\subsection{Parametric optimisation}

As a result of the parametric optimisation of the headstock, three dimensions of the body were proposed. They are characterised by varying degrees of mass reduction with the simultaneous decrease in static stiffness prevailing in these three cases. As a result, the first natural frequency of the body was increased. Based on [1], the evaluation function described by the dependence (1) has been proposed.

$$
F=\frac{\sum f_{i}^{\frac{1}{B}}}{m},
$$

where: $f_{i}$ is static stiffness index in the direction of force, $\mathrm{N} / \mu \mathrm{m} ; m$ is mass, $\mathrm{kg}$.

The highest evaluation function was obtained for the proposal defined as "candidate 3" (Table 3). However, these results are not satisfactory due to the fact that stiffness is significantly reduced, especially in the $\mathrm{Y}$-axis direction. A summary of results before and after the optimisation is presented in Table 4 and Fig. 6.

Results of parametric optimisation of the headstock wall thickness

Table 3

\begin{tabular}{|c|c|c|c|c|c|c|c|c|c|c|}
\hline \multirow{2}{*}{ Model } & \multicolumn{6}{|c|}{ Static stiffness } & \multirow{2}{*}{ Mass, kg } & \multirow{2}{*}{$\Delta, \%$} & \multirow{2}{*}{$1^{\text {st }}$ modal frequency, $\mathrm{Hz}$} & \multirow{2}{*}{$\Delta, \%$} \\
\hline & $\mathrm{X}, \mathrm{N} / \mu \mathrm{m}$ & $\Delta, \%$ & $Y, \mathrm{~N} / \mu \mathrm{m}$ & $\Delta, \%$ & $Z, \mathrm{~N} / \mu \mathrm{m}$ & $\Delta, \%$ & & & & \\
\hline Model 1 & 115,4 & 0 & 340,4 & 0 & 169,1 & 0 & 411,2 & 0 & 132,9 & 0 \\
\hline Candidate 1 & 126,4 & 9,5 & 323,6 & $-4,9$ & 200,8 & 18,8 & 383,5 & $-6,7$ & 154,2 & 16,0 \\
\hline Candidate 2 & 110,6 & $-4,2$ & 286,2 & $-15,9$ & 180,8 & 6,9 & 355,2 & $-13,6$ & 152,6 & 14,8 \\
\hline Candidate 3 & 102,7 & $-11,0$ & 258,1 & $-24,2$ & 174,6 & 3,3 & 344,8 & $-16,1$ & 152,1 & 14,5 \\
\hline
\end{tabular}
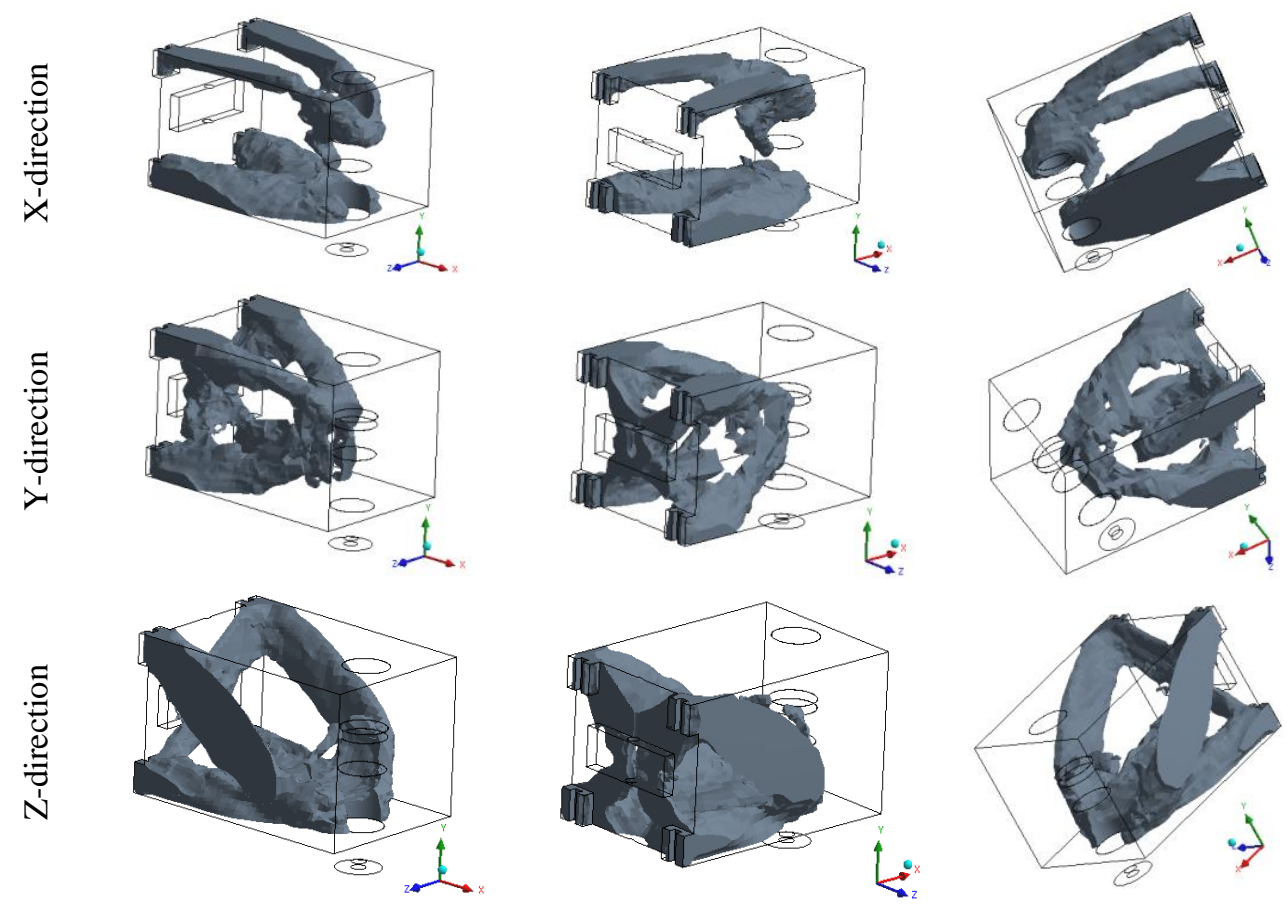

Fig. 8 The form of the headstock proposed in the shape optimisation results with the assumption of $80 \%$ weight reduction and load in the three main directions 


\subsection{Topology optimisation}

The parametric optimisation of the headstock body proposed by the designer did not give the expected results. For this reason, it was decided to optimise the form of the body and then re-optimise it basing on that. At the same time, the possibility of using other materials was assumed. Fig. 7 presents the results obtained in topology optimisation for force applied in three directions as separate load cases with assumed mass reduction. As it can be observed each form is different, depending on the load direction. Superposition of the three different forms allows to obtain the final form of the headstock

Based on the results of the form optimisation, the CAD model of the body was developed (Fig. 8). The model was subjected to parametric optimisation, in which the values of the body walls thickness were assumed as the decisive variables (Fig. 9). The optimisation was carried out assuming grey cast iron, steel, aluminium alloy and magnesium alloy as the body material. The properties of the selected body materials are presented in Table 5 .
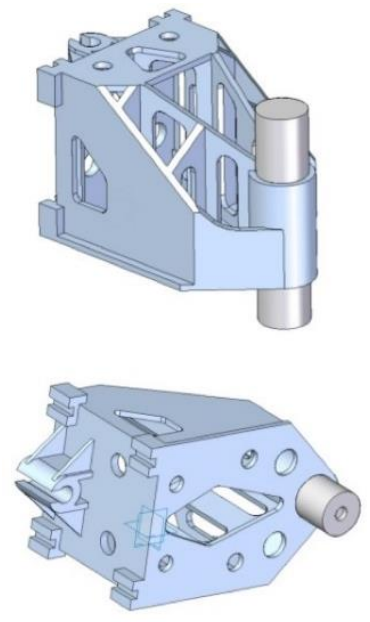

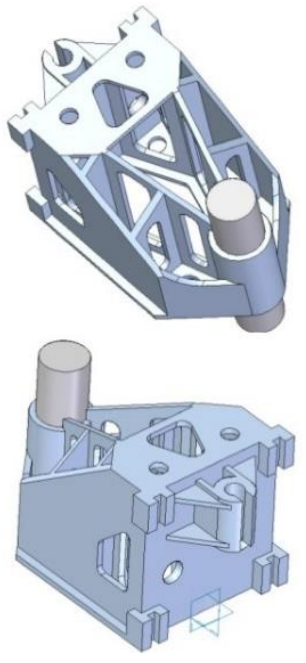

Fig. 9 The form of the headstock proposed as a result of shape optimisation
Table 4

Properties of materials selected for parametric optimisation of the headstock body [23, 24]

\begin{tabular}{|c|c|c|c|}
\hline Material & $\begin{array}{c}\text { Density, } \\
\mathrm{kg} / \mathrm{m}^{3}\end{array}$ & $\begin{array}{c}\text { Young's modu- } \\
\text { lus, MPa }\end{array}$ & $\begin{array}{c}\text { Poisson`s } \\
\text { number }\end{array}$ \\
\hline Cast iron & 7200 & $1.10 \mathrm{E}+05$ & 0,28 \\
\hline Steel & 7850 & $2.00 \mathrm{E}+05$ & 0,30 \\
\hline Aluminium alloy & 2700 & $6.89 \mathrm{E}+04$ & 0,33 \\
\hline Magnesium alloy & 1800 & $4.50 \mathrm{E}+04$ & 0,35 \\
\hline
\end{tabular}

The comparison of the optimisation results and the selection of the most advantageous solution was made on the basis of the assessment function proposed previously Eq. (1). It was also assumed that as a result of the optimisation, the reduction of static stiffness is not acceptable in relation to the solution originally proposed by the constructor. The optimisation results for different body materials are presented in Table 5, while Table 6 lists the thickness of the body walls depending on the material proposed.

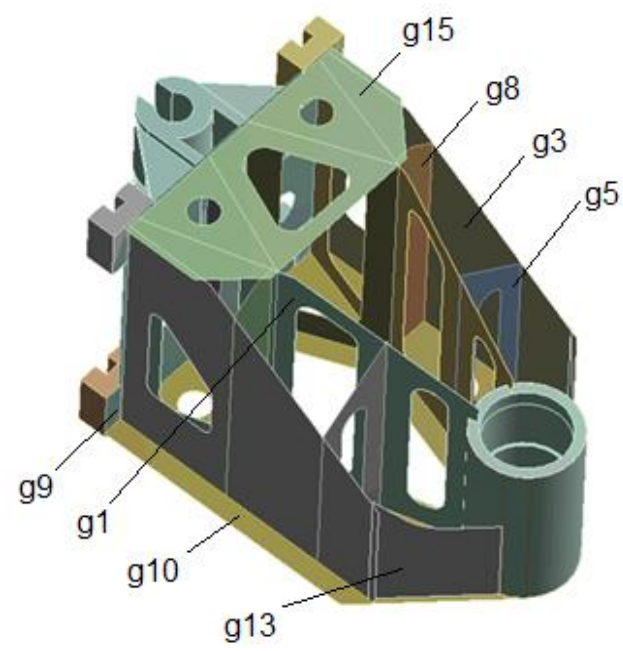

Fig. 10 Determination of wall thickness for the optimisation of the parametric headstock body

Table 5

Comparison of the spindle headstock optimisation results

\begin{tabular}{|c|c|c|c|c|c|c|c|c|c|c|c|}
\hline \multirow{2}{*}{ Model } & \multicolumn{6}{|c|}{ Static stiffness } & \multirow{2}{*}{ Mass, $\mathrm{kg}$} & \multirow{2}{*}{$\Delta, \%$} & \multirow{2}{*}{$\begin{array}{l}1^{\text {st }} \text { modal } \\
\text { frequency, } \\
\qquad \mathrm{Hz}\end{array}$} & \multirow{2}{*}{$\Delta, \%$} & \multirow{2}{*}{$\begin{array}{l}\text { Assessment func- } \\
\text { tion value }\end{array}$} \\
\hline & $X, \mathrm{~N} / \mu \mathrm{m}$ & $\Delta, \%$ & $Y, \mathrm{~N} / \mu \mathrm{m}$ & $\Delta, \%$ & $Z, \mathrm{~N} / \mu \mathrm{m}$ & $\Delta, \%$ & & & & & \\
\hline $\begin{array}{l}\text { original body } \\
\text { - cast iron }\end{array}$ & 115,4 & 0 & 340,4 & 0 & 169,1 & 0 & 411,2 & 0 & 132,9 & 0 & 0.0423 \\
\hline \begin{tabular}{|c|} 
original body after \\
parametric optimisation \\
"candidate 3" (cast iron) \\
\end{tabular} & 102,7 & 33 & 285,1 & $-24,2$ & 174,6 & 3,3 & 344,8 & $-16,1$ & 152,1 & 14,5 & 0,0483 \\
\hline \begin{tabular}{|c|}
$\begin{array}{c}\text { body after topology and } \\
\text { parametric optimisation } \\
\text { (aluminium alloy) }\end{array}$ \\
\end{tabular} & 153,5 & 36,8 & 347,3 & 2,0 & 207,4 & 22,7 & 183,0 & $-55,5$ & 198,5 & 49,4 & 0,1000 \\
\hline \begin{tabular}{|c|}
$\begin{array}{c}\text { body after topology and } \\
\text { parametric optimisation } \\
\text { (cast iron) }\end{array}$ \\
\end{tabular} & 157,9 & 36,8 & 427,9 & 25,7 & 217,7 & 28,7 & 323,0 & $-21,4$ & 173,7 & 30,8 & 0,0587 \\
\hline $\begin{array}{c}\text { body after topology and } \\
\text { parametric optimisation } \\
\text { (magnesium alloy) }\end{array}$ & 169,9 & 42,7 & 404,1 & 18,7 & 169,2 & 0 & 190,8 & $-53,6$ & 159,4 & 20 & 0,0986 \\
\hline \begin{tabular}{|c|}
$\begin{array}{c}\text { body after topology and } \\
\text { parametric optimisation } \\
\text { (steel) }\end{array}$ \\
\end{tabular} & 131,4 & 13,8 & 372,7 & 9,5 & 234,6 & 38,7 & 210 & $-48,9$ & 207,2 & 56 & 0,0879 \\
\hline
\end{tabular}


List of body wall thickness after parametric optimisation

\begin{tabular}{|c|c|c|c|c|}
\hline \multirow{3}{*}{ 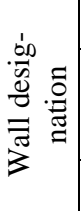 } & \multicolumn{4}{|c|}{ Body form (material) } \\
\hline & $\begin{array}{l}\text { Body after topology and } \\
\text { parametric optimisation } \\
\text { (aluminium alloy) }\end{array}$ & $\begin{array}{l}\text { Body after topology and par- } \\
\text { ametric optimisation (cast } \\
\text { iron) }\end{array}$ & $\begin{array}{l}\text { Body after topology and par- } \\
\text { ametric optimisation (magne- } \\
\text { sium alloy) }\end{array}$ & $\begin{array}{l}\text { Body after topology and par- } \\
\text { ametric optimisation (steel) }\end{array}$ \\
\hline & \multicolumn{4}{|c|}{ Wall thickness [mm] } \\
\hline g1 & 38,85 & 31,38 & 69,51 & 17,14 \\
\hline g2 & 34,28 & 13,92 & 64,19 & 9,67 \\
\hline g3 & 10,09 & 10,05 & 5,87 & 5,86 \\
\hline $\mathrm{g} 4$ & 11,50 & 10,66 & 41,94 & 4,74 \\
\hline g5 & 25,16 & 10,17 & 18,65 & 4,94 \\
\hline g6 & 37,92 & 30,73 & 78,92 & 10,50 \\
\hline g7 & 37,37 & 20,35 & 72,88 & 10,33 \\
\hline g8 & 32,11 & 30,08 & 10,66 & 6,53 \\
\hline
\end{tabular}

\section{Conclusions}

The results of the spindle head optimisation presented in this article indicate the possibility of reducing the weight of the body by up to half in relation to the body designed in the traditional way. In addition, the static rigidity of such solution, not only remains unchanged, but can also be significantly increased.

Comparison of the spindle headstock optimisation results shows that the highest value of the assessment function is characterised by the body made of aluminium alloy. A slightly lower value of the function was obtained for the body made of magnesium alloy, however, the body made of this type of material would be very expensive [4, 23]. For the steel body, the rating function gives way to the abovementioned constructions, however, due to the cost of performance, this solution seems to be the most beneficial one. In all three cases, the weight reduction is around $50 \%$. In some cases, the static stiffness has also been increased by more than $30 \%$. As a result, the first natural frequency is increased from $20 \%$ to over $50 \%$.

It can therefore be concluded that obtaining the optimal design of the machine body, due to the minimum mass and maximum static stiffness, in particular the body of a moving HSM machine tool, requires an interdisciplinary approach to the optimisation. The optimisation should take into account the possibility of changing the body material and its form and dimensions. At the same time, the technological capabilities of the body's construction should be taken into account, depending on the material used and its dimensions, as well as the construction costs. The experimental verification of the entire body can be carried out when the prototype of the headstock is also created.

\section{References}

1. Aggogeri, F.; Merlo, A.; Mazzola, M. 2010. Multifunctional structure solutions for Ultra High Precision (UHP) machine tools, International Journal of Machine Tools \& Manufacture 50: 366-373.

2. Fortunato, A.; Ascari, A. 2013. The virtual design of machining centers for HSM: Towards new integrated tools, Mechatronics 23(3): 264-278.
3. Herrada, F. J.; García-Martínez, J.; Fraile, A.; Hermanns, L. K. H.; Montáns, F. J. 2017. A method for performing efficient parametric dynamic analyses in large finite element models undergoing structural modifications, Engineering Structures 131: 625-638.

4. Uriarte, L.; Zatarain, M.; Axinte, D.; Yagüe-Fabra, J.; Ihlenfeldt, S.; Eguia, J.; Olarra, A. 2013. Machine tools for large parts, CIRP Annals - Manufacturing Technology 62(2):731-750.

5. Gomez-Acedo, E.; Olarra, A.; Orive, J.; Norberto, L.; de la Celle, L. 2013. Methodology for the design of a thermal distortion compensation for large machine tools based in state-space representation with kalman filter, International Journal of Machine Tools and Manufacture 75: 100-108.

6. Kosmol, J.; Wilk, P. 2013. Comparison of optimization methods based on primitive bodies of machine tools and preliminary design", Proceedings of the Fourteenth International Conference on Civil, Structural and Environmental Engineering Computing, Stirlingshire: CivilComp Press: paper 113.

7. Kosmol, J.; Wilk, P. 2011. Experimental verification of a numerical model of a vertical machining centre, Proceedings of the Thirteenth International Conference on Civil, Structural and Environmental Engineering Computing, Stirlingshire: Civil-Comp Press: paper 148.

8. Wilk, P.; Kosmol, J. 2007. Optimisation of frames of a milling machine tool using genetic algorithms and the finite element method, Proceedings of the Ninth International Conference on the Application of Artificial Intelligence to Civil, Structural and Environmental Engineering: 1-13.

9. Lehrich, K.; Wąsik, M.; Kosmol, J. 2018. Identifying the causes of deterioration in the surface finish of a workpiece machined on a rail wheel lathe, Eksploatacja i niezawodnosc - Maintenance and reliability 20(3): 352-358. http://dx.doi.org/10.17531/ein.2018.3.2.

10. Wąsik, M.; Lis, K.; Lehrich, K.; Mucha, L. 2018. Model-Based Dynamic Structural Modification of Machine Tools, Shock and Vibration 2018: Article ID 3469171. https://doi.org/10.1155/2018/3469171.

11. LMS CADA-PC user manual, LMS, Leuven, 1994. 
12. ModalVIEW Operating tutorial R2 2012, Available from Internet: http://absignal.co.

13. Weise, T. 2009. Global Optimization Algorithms - Theory and Application. Available from Internet: http://www.it-weise.de.

14. Bendsøe, M. P. 1995. Optimization of structural topology, shape and material, Springer Verlag, Berlin, Heidelberg, New York.

15. Sun, T.; Lian, B. 2018. Stiffness and mass optimization of parallel kinematic machine, Mechanism and Machine Theory120: 73-88.

16. Jacobsen, J. B.; Olhoff, N.; Ronholt, E. 1997. Generalizad shape optimization of three-dimensional structures using materials with optimum microstructures, Report of Institute of Mechanical Engineering, Aalborg University, Denmark.

17. Payten, W.M.; Law, M. 1997. Optimising multiple load case structures using a self-organising density approach, Proceedings of WCSMO-2 (World Congress on Structural and Multidisciplinary Optimization): 133138.

18. Ramm, E.; Bletzinger, K.U.; Reitinger, R.; Maute, K. 1994. The challenge of structural optimization. Advances in Structural Optimization, in: Topping B.H.V., Papadrakakis M., Advanced in Structural Optimization, Proc. Int. Conf. on Computational Structures Technology: 27-52.

19. Rietz, A. 2001. Sufficiency of a finite exponent in SIMP (power law) methods, Structural and Multidisciplinary Optimization 21: 159-163.

20. Rozvany, G. I. N.; Zhou, M.; Birker, T. 1992. Generalized shape optimization without homogenization, Structural Optimization 4: 250-252.

21.Stolpe, M.; Svanberg, K. 2001. On the trajectories of penalization methods in topology optimization, Structural and Multidisciplinary Optimization 21: 128-139.

22. Chandrupatla, T. R.; Belegundu, A. D. 1991. Introduction to finite element method in engineering, Prentice-Hall, London.

23. Davies, G. J.; Zhen S. 1983. Metallic foams: their production, properties and applications, Journal of Materials Science 18: 1899-1911.

24. Suhl, J. D.; Lee, D. G. 2002. Composite machine tool structures for high speed milling machines, CIRP Annals - Manufacturing Technology 51/1: 285-288.
M. Wąsik, K. Lehrich, K. Lis

OPTIMISATION OF A SPINDLE BODY CONSIDERING THE VIBRATION PREDICTION OF THE ENTIRE MILLING CENTRE CONSTRUCTION

\section{S u m m a r y}

Static and dynamic properties of machine tools have a decisive influence on their accuracy. In case of HSM machine tools, the phenomena associated with them are additionally strengthened by high machining parameters. In order to predict a machine tool behaviour at the design stage, it is necessary to use numerical methods to simulate for its simulation. Thanks to the use of this type of software, it is possible to perform the next step, i.e. the optimisation of the structure. In case of machine tools, due to the multiplicity of factors affecting its accuracy, this should be a multicriterial optimisation. This article presents the results of a vertical milling centre spindle body optimisation using the Finite Element Method. The results of static stiffness and vibration frequency analysis for three bodies (i.e. the body of the form and dimensions proposed by the constructor, the body after parametric optimisation and the body after the form and parametric optimisation including use of different materials) were compared. The optimisation tools available in the ANSYS system were used for the simulation. The calculations were preceded by experimental research and modifications of dynamic parameters performed on their basis using the author's methodology to determine the behaviour of a partially existing structure for different masses of the body being optimised.

Keywords: optimisation, FEM, machine tool, HSM.

Received October 15, 2019 Accepted February 17, 2021 